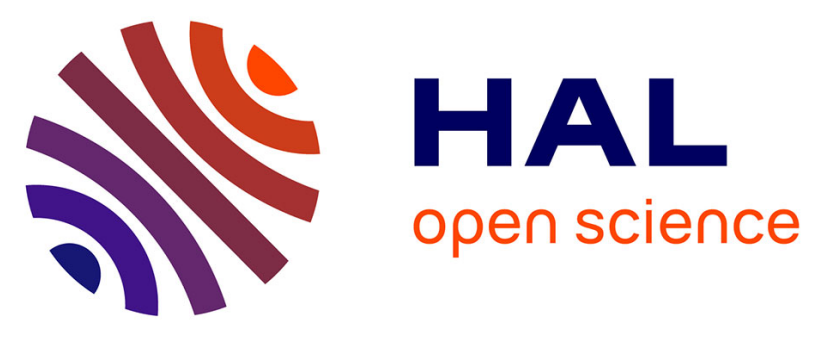

\title{
Consequences of Extended Spectrum Beta-Lactamase-Producing Enterobacteriaceae and Methicillin-Resistant Staphylococcus aureus Carriage in Awaiting Liver Transplant Patients
}

\author{
Bianca Magro, Alessandra Mazzola, Mona Munteanu, Claire Goumard, \\ Valérie Martinez, Denis Bernard, Olivier Scatton, Salvatore Battaglia, Ciro \\ Celsa, Calogero Cammà, et al.
}

\section{- To cite this version:}

Bianca Magro, Alessandra Mazzola, Mona Munteanu, Claire Goumard, Valérie Martinez, et al.. Consequences of Extended Spectrum Beta-Lactamase-Producing Enterobacteriaceae and MethicillinResistant Staphylococcus aureus Carriage in Awaiting Liver Transplant Patients. Liver Transplantation, 2020, 10.1002/lt.25897 . hal-03050199

\section{HAL Id: hal-03050199 \\ https: / hal.sorbonne-universite.fr/hal-03050199}

Submitted on 10 Dec 2020

HAL is a multi-disciplinary open access archive for the deposit and dissemination of scientific research documents, whether they are published or not. The documents may come from teaching and research institutions in France or abroad, or from public or private research centers.
L'archive ouverte pluridisciplinaire HAL, est destinée au dépôt et à la diffusion de documents scientifiques de niveau recherche, publiés ou non, émanant des établissements d'enseignement et de recherche français ou étrangers, des laboratoires publics ou privés. 
Article type : Original Articles

TITLE: Consequences of Extended Spectrum Beta-Lactamase-Producing Enterobacteriaceae and Methicillin-Resistant Staphylococcus aureus Carriage in Awaiting Liver Transplant Patients

Consequences of ESBLE and MRSA carriage in awaiting liver transplant patients.

\section{MANUSCRIPT ID ID LT-20-298}

Bianca Magro ${ }^{1,2}$, MD, Alessandra Mazzola ${ }^{1,3}, \mathrm{MD}$, PhD, Mona Munteanu ${ }^{4}, \mathrm{MD}, \mathrm{PhD}$, Claire Goumard $^{5}, \mathrm{MD}$, Valerie Martinez ${ }^{6}, \mathrm{MD}, \mathrm{PhD}$, Denis Bernard ${ }^{7}, \mathrm{MD}$, Olivier Scatton ${ }^{5}$, MD, PhD, Salvatore Battaglia ${ }^{8}, \mathrm{MD}$, Ciro Celsa ${ }^{2,9}, \mathrm{MD}$, Calogero Cammà², MD, PhD, Filomena Conti ${ }^{1,3,4}, \mathrm{MD}, \mathrm{PhD}$.

${ }^{1}$ APHP, Unité Médicale de Transplantation Hépatique Hôpital Pitié Salpêtrière,Paris, France.

2 Section of Gastroenterology and Hepatology, Department of Health Promotion, Mother and Child Care, Internal Medicine and Medical Specialties, University of palermo, Italy

${ }^{3}$ Sorbonne Université, INSERM U938, Centre de recherche Saint-Antoine (CRSA), Paris, France, ${ }^{4}$ Sorbonne Université, INSERM, Institute of Cardiometabolisme and Nutrition (ICAN), Paris, France.

${ }^{5}$ APHP, Unité de Chirurgie Hépatobiliaire et Transplantation hépatique, Hôpital Pitié Salpêtrière, Paris, France.

${ }^{6}$ APHP, Service de Maladies Infectieuses, Hôpital Pitié Salpêtrière, Paris, France.

${ }^{7}$ APHP, Service d'Anesthésie et Réanimation, Hôpital Pitié Salpêtrière, Paris, France.

${ }^{8}$ Department of Economics, Business and Statistics (SEAS), University of Palermo, Italy ${ }_{9}$ Department of Surgical, Oncological and Oral Sciences (Di.Chir.On.S.), University of Palermo, Italy

\section{Corresponding Author: Bianca Magro, MD}

Section of Gastroenterology and Hepatology, PROMISE,

University of Palermo, Piazza delle Cliniche, 2, 90127 Palermo, Italy.

This article has been accepted for publication and undergone full peer review but has not been through the copyediting, typesetting, pagination and proofreading process, which may lead to differences between this version and the Version of Record. Please cite this article as doi: 10.1002/LT.25897

This article is protected by copyright. All rights reserved 
Phone: +39 3925277473. Fax: +39 0916552276

E-mail: bianca_magro@hotmail.it

\section{AUTHOR CONTRIBUTIONS:}

Concept and design: Bianca Magro, Alessandra Mazzola, Filomena Conti

Manuscript writing: Bianca Magro, Alessandra Mazzola

Final approval of manuscript: all authors

ACKNOWLEDGEMENTS: No one

FUNDING: No one.

CONFLICT OF INTEREST AND FINANCIAL DISCOLSURE: Authors have nothing to disclose.

Guarantor of the article: Bianca Magro

Short title: ESBLE fecal carrier and liver transplantation

Words count: 3441

Keywords: ESBLE, fecal carriage, cirrhosis, liver transplantation

\section{Abbreviations}

ESBLE: Extended spectrum beta-lactamase producing Enterobacteriaceae MRSA: Methicillin-resistant Staphylococcus aureus

LT : liver transplantation

MDROs: Multi-drug resistant organism

LRC : liver-related complications 
HCC : hepatocellular carcinoma

HR: Hazard Ratio

SBP: sponatneous bacterial peritonitis

HRS: hepatorenal syndrome

HE: hepatic encephalopathy

UTI: urinary tract infection

This article is protected by copyright. All rights reserved 


\section{ABSTRACT:}

Background: Infections in cirrhotic patients are associated with liver-related complications (LRC), especially, in patients awaiting liver transplantation (LT). The aim of this study was to evaluate the impact of Methicillin-Resistant-Staphylococcus-Aureus (MRSA) and ExtendedSpectrum-Beta-Lactamase (ESBL) colonization, on infections and LRC on the waitlist and on infections after LT.

Method: We retrospectively included 250 of 483 cirrhotic placed on waitlist for LT from December 2015 to January 2018, screened for MRSA or ESBLE, at the time of waitlist placement and after LT.

Results: $76 \%$ of patients were male with mean age of $57.5 \pm 10$, the most frequent cause of liver disease was alcohol (39\%). Median MELD score was 19 (12-28). Only 1 patient was positive for MRSA, $19 \%$ of patients $(n=47)$ were ESBLE fecal carriage at the moment waitlist placement and $15 \%(n=37)$ after LT. Infection free-survival on the waitlist and after LT, according to fecal carriage status, was not statistically different between two groups. LRC-free-survival at 6 and 12 months was significantly lower in ESBLE fecal carriage [HR 1; $<$ 0.04)]. MELD score > 19 [HR $3 ;(p=0.01)]$ and occurrence of infection during the first 3 months on the waitlist [HR 4.13; $(p<0.001)]$ were independent risk factors for LRC occurrence at multivariate analysis

Conclusions: Our study is the first showing that, in a cohort of cirrhotic patients waiting for LT LRC-free survival is lower in ESBLE fecal carriage, but infection free survival is not different in the two groups. 


\section{INTRODUCTION:}

Infections are common in cirrhotic patients, about $25-30 \%$ for each hospitalization, and they develop as a consequence of the immune dysfunction that occurs progressively during the course of cirrhosis. When infections occur, they were associated with an increased risk of liverrelated complications (LRC), liver failure and mortality. The overall mortality of infected patients was reported to be as high as $38 \%$ (odds ratio for death of infected vs. non-infected patients of 3.75). Incidence of infections, could represent a further prognostic stage, defining the "critically ill cirrhotic" and it increases mortality 4 -fold: $30 \%$ of patients die within 1 month and another $30 \%$ die by 1 year. $(1,2)(1)(2)$

Bacterial infections, especially those involving gram-negative bacteria, represent a major complication in liver transplant recipients, the frequency ranging between $20 \%$ and $80 \%$ of cases.

(3)

Moreover, in patients with advanced cirrhosis, prevalence of multi drug resistance organism (MDROs) infections is alarmingly increased, mainly in nosocomial setting. Repeated hospitalizations, invasive procedures and the expositions to antibiotics, as prophylaxis (long-term primary and secondary prophylaxis of spontaneous bacterial peritonitis (SBP) and short-term prophylaxis in upper gastrointestinal bleeding) or as treatment, seem to have contributed to increase the prevalence of MDROs infections across different geographical areas in the cirrhotic population. (4)

In the field of the antibiotic resistance an important role is played by the spread of ESBLproducing Enterobacteriaceae (ESBLE) especially infection related to E. Coli, most represented in Asia, and Klebsiella Pneumonia in Latin America. (5) Guidelines for infection management to reduce MDROs transmission in hospital, recommended to implement screening culture trough rectal swab at the admission and to realize it weekly until a new infection or colonization but no consensus exists on the optimal timing and interval. (6)

Although, there are few data concerning the prevalence of ESBLE fecal carriage in cirrhotic patients. Recent studies suggest that it is similar to the general population prevalence $(15.7 \%)$. (7)

However, as a consequence of the recurrent hospitalizations, cirrhotic patients could be considered such as "the vehicle" of MDROs between the healthcare environment and the general population. This spread is difficult to control because of the potential huge intestinal reservoir and the international travels in a globalized world. (8) Infections caused by MDROs are associated to poor prognosis increasing morbidity and mortality, both in the pre- and post-transplant settings. The problem of MDR is particularly challenging in patients awaiting LT. The use of inappropriate empiric antimicrobial in septic shock secondary to any type of infection or to SBP is associated 
with an adjusted odds ratio of death of 1.1 and 1.9 , respectively for every hour delay in appropriate antibiotic therapy. (9)(10)

Before LT, colonization with staphylococcus methicillin resistant (MRSA) or ESBLE is an independent risk factor for post-transplant infections. Especially in the early postoperative period, infections are caused by bacteria that have colonized the digestive tract or the oropharynx before. Bert et al. in their retrospective study demonstrated that previous ESBL-producing isolate infection, recent exposure to a b-lactam agent, and an history of SBP are risk factors for preoperative fecal carriage of ESBLE in liver transplant recipients. Moreover, fecal carrier was an independent risk factor for post-transplant infections. (7)(11)

An important clinical problem is for patients hospitalized for SBP having a risk of ESBLE infection (positive culture at rectal swab), because there isn't any recommendation for the empiric antibiotic treatment. (12)

All the studies regarding this issue were based on a single rectal swab at the moment of LT, there are no data on clinical impact of ESBLE fecal carriage on the waitlist.

The aim of this study is to evaluate impact of MRSA and ESBLE colonization at 6 and 12 months on infections and liver-related complications (LRC) during time on the waitlist and infections after LT. 


\section{METHODS}

\section{Study population:}

We retrospectively included 250 of 483 cirrhotic placed on waitlist for LT from December 2015 to January 2018 in our liver transplant center at Pitié-Salpêtrière hospital, that correspond to the population systematically screened for MRSA or ESBL carriage with nasal and rectal swab at the time of waitlist placement and in the next six months after LT (Figure 1). 216 patients were transplanted and 34 died before LT. We analyzed consecutively all data. Inclusion criteria were: i) cirrhotic patients, according to histological, clinical, biochemical, ultrasound, and/or endoscopic findings; ii) patients on the waitlist for LT; iii) screened for MRSA or ESBLE carriage with nasal/rectal swab at the moment of waitlist placement and after six months within LT.

The exclusion criteria were: i) non-cirrhotic patients; ii) patients not screened at nasal or rectal swab at the moment of waitlist inscription; iii) patients waiting for re-transplantation.

All medical major health events including LRC, infections, re-hospitalisation or deaths were collected.

\section{Outcomes:}

The primary outcome was to evaluate the clinical impact of ESBLE fecal carriage on infectionsfree-survival before and after LT, and on LRC-free-survival during time on the waitlist respectively at 6 and 12 months. The secondary outcome was to evaluate the overall survival rate on the waitlist according to ESBLE fecal carriage and also to individuate risk factors of LRC.

Variables:

-Infections before LT: SBP, pneumonia, urinary tract infection (UTI), cholangitis, meningitis, colitis, skin and soft tissues infections, sepsis. Infection-free-survival was considered from the time of waitlist placement to the time of infections occurrence or the time of LT/death. (13) -Infections after LT: pneumonia, UTI, biliary infections, bacteremia, cutaneous infections. The infection-free-survival was considered from LT to the time of occurrence of the infections or last follow-up/death. (13)

-LRC: upper gastrointestinal bleeding (UGB), hepatorenal syndrome (HRS), SBP, hepatic encephalopathy $(\mathrm{HE})$ that occur on waitlist period. The LRC-free-survival was defined from the time of placement on waitlist to the time of LRC occurrence or the time of LT/death. (14)

- Waitlist mortality: time from waitlist placement to time of death or LT, no matter the cause, at any time, during all the follow-up period.

\section{Data collection:}


Data sources to complete the prospective database were outpatient or inpatient reports, radiology reports, operative reports, and laboratory or pathology reports, on digital or paper support. Moreover, a complementary source of data was represented by the CRISTAL database of Agence National de la Biomedicine ( https://www.sipg.sante.fr/portail/).

The quality of data management was compliant to a reference methodology on personal data processing and protection (database hosted on secured hospital servers - CNIL n²208386 v 0). For this reason a dedicated patient consensus was not required.

\section{Microbiological assessment:}

Rectal and nasal swabs were systematically performed once at the time of waitlist placement for LT and within six months after LT, regardless of the indication to be hospitalized in election or in urgency.

A rectal swab specimen was obtained and plated into a selective commercial agar plate (ESBL agar, bioMerieux, Marcy l'Etoile, France). Identification of ESBL isolates was done by the doubledisk synergy test on Mueller-Hinton agar and, when appropriate, Mueller-Hinton agar containing cloxacillin. Identification to the species level was done by the API20E method. Antimicrobial drug susceptibility was tested by the Mueller-Hinton agar diffusion method and interpreted according to the recommendations of the Committee of the French Society for Microbiology.

\section{Statistical analysis:}

Data were analyzed with the NCSS-12.0 statistical package. Data for continuous variables are presented as mean and standard deviation (SD) or as median and range, and data for categorical variables as frequency and percentage. Differences between continuous data were analyzed by Student $t$ test or Chi square test was used for dichotomous or categorical variables. Survival probabilities were estimated according to the Kaplan Meier method. The Log Rank test was used to compare patient survival groups. The stepwise Cox proportional hazard regression model was used to assess the independent factors of LRC on the waitlist. Variables with a $p$ value $<0.1$ at univariate analysis were inserted in a multivariate model. The multivariate analysis was adjusted for LRC at baseline

A $p$ value $<0.05$ was considered statistically significant. A non parametric competing risks analysis was performed in order to estimate separately the sub distribution cumulative incidence functions (CIFs) of transplant and death, according to Fine and Gray approach (16) The Gray's 
test was used to evaluate hypotheses of equality of sub distribution CIFs according to the fecal carriage status (positive versus negative) (17)

\section{RESULTS:}

Patients:

Baseline characteristics of the 250 cirrhotic patients are shown in Table 1. Seventy-six percent of patients were male with a mean age of $57.5 \pm 10$, the most frequent cause of liver disease was alcohol (39\%). Median MELD score was 19 (12-28) and 21\%of patients had hepatocellular carcinoma (HCC). One patient had a positive nasal swab for Staphylococcus aureus at waitlist placement.

Prevalence rate of LRC on the waitlist was: $17 \%(n=50) \mathrm{HE}, 6 \%(n=19)$ SBP, $13 \%(n=37) \mathrm{HRS}$ and $12 \%(n=34)$ UGB. Nineteen percent of patients $(n=47)$ were ESBLE fecal carriage at the time of place on waitlist and $15 \%(n=37)$ after $L T$.

The prevalence rates of organism isolated from rectal swab at the time of waitlist were: $53 \%$ Escherichia Coli, 38\% Klebsiella Pneumoniae, 0.04\% Enterobacter Clocae and 0.02\% Pseudomonas Aeruginosa; after LT were 48\% E.Coli and 43\% K. Pneumoniae.

Moreover, median MELD score was significantly higher in ESBLE fecal carriage compared to Non- ESBLE fecal carriage: [23(19-28) vs. 18(16-20); $\mathrm{p}<0.01]$, also HCC rate was significantly different in the two groups $[11,3 \%(n=6)$ vs. $23 \%(n=47) ;(p=0.01)]$, such as viral $[20 \%(n=9)$ vs. $26 \%(n=50),(p=0.01)]$ and alcohol- related cirrhosis $[30 \%(n=14)$ vs. $37 \%(n=70) ;(p=0.04)]$. There 
wasn't any significant difference between the two groups regarding previous treatment with norfloxacin and rifaximin ( $p=0.9$ and $p=0.7$, respectively). No significant difference was found for antibiotic treatments, hospitalization rate in intensive or semi-intensive care-unit (ICU or SICU) in the last 3 months $(p=0.3$ and $p=0.6$, respectively). Median time on the waitlist was 4 (3-4) months, and median time of follow-up after LT was 17 (4-55) months.

\section{Primary outcomes:}

\section{- Impact of ESBLE fecal carriage on infection}

Median time of infection occurrence before LT was significantly different in ESBLE fecal carriage: 2 (1-3) months vs. $4(2-5)$ months in Non-fecal carriage $(p=0.06)$.

Infection free-survival rates at 6 and 12 months on the waitlist according to EBLSE fecal-carriage was not statistically different between two groups [HR 1.2; $95 \% \mathrm{Cl}(0.5-3.29) ; p=0.63]$; [HR: 1.5 , $95 \% \mathrm{Cl}(0.6-3.7) ; p=0.28)$ ] (Figure 2). Among infections on the waitlist, $51 \%(n=33)$ percent was related to ESBLE and the most frequent were pneumonia $(30 \%, n=20)$ and SBP $(30 \%, n=20)$. In $50 \%(n=32)$ of cases a germ was isolated and the most common was E. Coli $(36 \%, n=12)($ Table S).

Infection free-survival rates at 6 and 12 months after LT according to ESBLE Fecal carriage was not significantly different between the two groups [HR 0.99; $95 \% \mathrm{Cl}(0.46-2.15) ; p=0.9$ ] (Figure 2).

After LT, $42 \%(n=23)$ of infections were due to ESBLE, the most common were: pneumonia (34\%, $\mathrm{n}=26)$. In $73 \%(\mathrm{n}=55)$ of cases a germ was isolated, the most common germs were $\mathrm{K}$. Pneumoniae (25\%, n=14) and E. Coli $(14 \%, n=8)$ (Table S). Among 47 fecal carriers, 13 persist to be positive also after $L T$. The infection rate after $L T$ in patients who had a positive swab was $45,9 \%(\mathrm{~N}=17 / 37)$

\section{- Impact of ESBLE fecal carriers on LRC}

In our study we evaluate ESBLE fecal carriage impact on LCR occurrence during time on the waitlist. The median time of LRC occurrence was 2 (1-3) and $3(3-4)$ months $(p=0.2)$, in ESBLE fecal carriage vs. non ESBLE fecal carriage, respectively. LRC according to fecal carrier status were shown in Figure 3. HRS was significantly higher in the ESBLE fecal carriage compared to not one $[30 \%(n=12)$ vs. $14 \%(n=25),(p=0.02)]$

LRC-free-survival at 6 and 12 months was significantly lower in ESBLE fecal carriage vs. Nonfecal carriage: [HR 1.6; (95\% Cl 0.9-3; p<0.04)] (Figure 4).

\section{Secondary outcomes:}




\section{Waitlist survival}

Table 2 shows the outcomes of patients stratified according to the fecal carriage status. By competing risks analysis, the probability of death at 6 months was $12.7 \%(95 \% \mathrm{Cl} 5.1-24.1 \%)$ in patients with positive fecal carriage, and $10.4 \%(95 \% \mathrm{Cl} 6.7-15.1 \%)$ in patients with negative fecal carriage, respectively. The probability of death at 12 months was $14.9 \%$ (95\% Cl 6.3-26.7\%) in patients with positive fecal carriage, and $11.9 \%(95 \% \mathrm{Cl} 7.9-16.9 \%)$ in patients with negative fecal carriage, respectively. No significant differences were observed between patients with positive and negative fecal carriage $(p=0.721)$. (Figure S1)

In patients with $\mathrm{HCC}$, no differences were found in waitlist mortality between patients with positive and negative fecal carriage, by competing risks analysis ( $p=0.608)$. (Figure S2)

In patients who developed LRC and who had not HCC, no death competing events were observed. In these patients, the probabilities of transplant according to the fecal carriage status are showed in Figure S3.

The most common causes of death were: infection $(53 \%, n=18)$ such as pneumonia and SBP, and liver-related $(44 \%, n=15)$ such as hematemesis.

\section{- Predictors of liver related complications:}

Patients characteristics included in univariate and multivariate analysis were reported in Table 3. In our study, at multivariate analysis, MELD score > 19 [HR 3; $95 \% \mathrm{Cl}(1.8-5) ; p=0.01]$ and infection during the first three months on the waitlist [HR 4.13;95\% $\mathrm{Cl}(2.13-7.9) ; \mathrm{p}<0.001]$ were independent risk factors for LRC occurrence on the waitlist. (Table 3) SBP was censored as infection. 


\section{DISCUSSION}

In our retrospective study prevalence rate of ESBLE fecal carriage among cirrhotic patients is higher $(19 \%)$ than reported in literature $(15,7 \%)$. (7) This could mean that the spread of ESBLE colonization is increased in the last years, and it represents an important source of morbidity and mortality, especially for patients waiting for LT.

The recent multicentric study, conducted on 1302 cirrhotic patients, has shown that MDR bacterial infections are associated with a higher incidence of septic shock and higher in-hospital mortality at 28 days ( $29 \%$ vs $20 \%$; $P=0.014)$. Moreover, this study showed that MDR prevalence depends on the geographic area (73\% in India; $16 \%$ in United States and $24 \%$ in Canada) (18) Previous studies have investigated the role of the ESBLE fecal carriage on infections in a cohort of cirrhotic patients and especially after LT. Bert et al, in a cohort of 317 cirrhotic patients, demonstrated that pre-transplant ESBLE fecal carriage confers a high risk for infection (48\% vs. $6,7 \%, p>0.001$ ) with the same organism after LT. (7) A recent study of Logre et al. showed that about $40 \%$ of ESBLE carriers before transplantation develop infection with ESBLE after LT. But also, in this case authors used the rectal swab obtained before LT to analyze infections after LT.

Our study is the first that evaluate ESBLE fecal carriage impact before and after LT on relevant clinical outcomes. Contrary to published data, we reported any difference on infection-freesurvival before and after LT at 6 and 12 months between ESBLE fecal carriage and Non ESBLE fecal carriage [HR: $1.5,95 \% \mathrm{Cl}(0.6-3.7) ; p=0.28)$ ]; [HR 0.99; 95\% Cl (0.46-2.15); $p=0.9$ ]. But in our study, we considered for the survival analysis two rectal swab at different moments: placement on the waitlist and after LT.

After LT many variables can impact on infection occurrence such as ICU hospitalization, surgery and their related complications, and a single rectal swab, probably, cannot determinate infections occurrence.(19)(20)

While during the time on the waitlist it would be interesting to repeat rectal swab routinely to assess patient colonization and to minimize antibiotic use. (4) The presence of a single specimen is one of the limits of our study, because we don't know if the fecal carriage status changes and how it changes during pre-transplant period. The retrospective design of the study cannot allow to explore all the fecal carriage variations.

Giannella et al. investigated in a large prospective cohort study (553 patients) the impact of colonization with carbapenemase-producing Enterobacteriaceae (CPE) on the CPE infection risk after LT, and they showed that CPE colonization at LT or acquired after LT were the strongest predictors of CPE infection after LT. In this study rectal swab was performed at the time of LT.(21)

This article is protected by copyright. All rights reserved 
Regarding the overall survival on the waitlist, there is no difference between the two groups [HR $1.57 ; 95 \% \mathrm{Cl} 95 \%$ (0.7-3.56); $\mathrm{p}=0.17$ ]. The most common cause of death is infection $(53 \%)$ and among the hepatic ones the most common was SBP (40\%).

To our knowledge our study is the first that evaluates impact of ESBLE colonization on LCR on the waitlist. Our results show a significant difference on LRC-free-survival on waitlist between the two groups at univariate analysis [HR 1.6; $(95 \% \mathrm{Cl} 0.9-3 ; \mathrm{p}<0.04)]$, even if this result is not confirmed in multivariate analysis. We want to underline the importance to identify colonized patients because of their higher risk of complication, ant it would be supposed that this kind of patients could be decolonized or it would be necessary an antibiotic treatment at the moment of the complication to reduce over infection or clinical worsening.

It is known that in cirrhosis the gut liver axis and the homeostasis of the immune system are altered. The increased intestinal permeability allows the bacterial translocation, bacterial products spread through the portal circulation, triggering an inflammatory and systemic response. This dysbiosis could lead to the development of LRC. (22) Moreover, bacterial translocation in cirrhotic patients is a crucial step leading to LRC, but little is known about the mechanism that could explain it. (1)

We explored the possible risk factors of LRC occurrence on the waitlist, in multivariate analysis and we identified: MELD score $>19$ [HR 3; 95\% Cl $(1.8-5) ; p=0.01]$ and time of infection during the first 3 months on the waitlist [HR 4.13; 95\% Cl $(2.13-7.9) ; p<0.001]$ as independent risk factors, but ESBLE fecal carriage is not confirmed [HR:1.37; $95 \% \mathrm{Cl}(-0.4-1.04) \mathrm{p}=0.3$ ]. Probably we need a bigger sample size to validate its role in this context. Dionigi et al. in their retrospective study showed how infection occurrence in cirrhotic patients defines another stage of disease, associated with higher morbidity and mortality despite of infection resolution. (23)

In a recent study, Kimman et al., reported that in cirrhotic patients with a MELD score between 15 and 25, SBP incidence is the most frequent infection and it increased mortality $(p=0.02$; HR $=$ 2.10), and patients included in our study have a similar MELD score. (24)

Infections in this setting of patients, waiting for $L T$, represent a big issue especially for public health and it is fundamental to have solid prevention strategies. Different studies, in non-cirrhotic population, tried different strategies of decolonization for ESBLE carriers, but they showed a moderate efficacy. (25)

A recent multicentric randomized trial evaluated, in a cohort of patients' carriers for ESBLE or CPE at stool culture, the possible decolonization by an antibiotic oral treatment followed by microbiota fecal transplantation (MFT). Sample size was small $(n=39)$, but $50 \%$ of MFT and $3 \%$ of control patients achieved decolonization (OR 3.3, 95\% 0.7e16.8), in this study non-cirrhotic patients were enrolled.(26) It seems to be necessary to validate the strength of rectal swab 
screening, decolonization strategies and also spread prevention, especially in the setting of LT recipients.

Our study presents different limits: the retrospective and monocentric design of the study, the small sample size, and the single rectal swab taken before and after LT. Moreover, data from patients placed on waitlist not screened for ESBLE or MRSA are not available. and we did not have the second swab for all patients swabbed at the moment of waitlist placement $(n=187 / 250)$. In conclusion, our study shows an increase of ESBLE colonization among cirrhotic patients in the last years (19\% vs $15 \%)$. This is the first study that reported a significant association of fecal carriage status and the occurrence of LRC in LT recipients. The implications of this study for us are significant: indeed, even if all the results are not significant, which is probably due to the small number of patients and the retrospective nature of the evaluation, sheds light on us by showing that ESBLE colonized patients have more LRC, and are therefore more likely to decompensate. We are convinced that this screening will help in the prevention of pre LT complications, whether infectious or not.

Future prospective investigations with a large simple size could be performed to clarify this data. It is important to underline that MELD score $>19$ and earliness of infections occurrence $(<3$ months) were the independent predictors of LRC. Moreover, our results didn't show a correlation between ESBLE fecal carriage status end infection occurrence before and after LT, probably because we have not done rectal swab routinely on waitlist and because after LT there are many variables that can impact on infections occurrence. It is necessary to optimize prevention strategies, and in this context the role and the validity of the rectal swab needs to be more explored by a prospective and multicentric studies, especially in cirrhotic patients.

\section{BIBLIOGRAPHY}

1. Jalan R, Fernandez J, Wiest R, et al. Bacterial infections in cirrhosis: A position statement based on the EASL Special Conference 2013. J. Hepatol. 2014;60:1310-1324.

2. Arvaniti V, D'Amico G, Fede G, et al. Infections in patients with cirrhosis increase mortality four-fold and should be used in determining prognosis. Gastroenterology 2010;139

3. Rubin $\mathrm{RH}$. The direct and indirect effects of infection in liver transplantation: pathogenesis, impact, and clinical management. [Internet]. Curr. Clin. Top. Infect. Dis. 2002;22:12554.[cited 2019 Oct 28] Available from: http://www.ncbi.nlm.nih.gov/pubmed/12520651

4. Fernández J, Bert F, Nicolas-Chanoine $\mathrm{MH}$. The challenges of multi-drug-resistance in 
hepatology. J. Hepatol. 2016;65:1043-1054.

5. Arias CA, Mendes RE, Stilwell MG, et al. Unmet needs and prospects for oritavancin in the management of vancomycin-resistant enterococcal infections. Clin. Infect. Dis. 2012;54

6. Tacconelli E, Cataldo MA, Dancer SJ, et al. ESCMID guidelines for the management of the infection control measures to reduce transmission of multidrug-resistant Gram-negative bacteria in hospitalized patients. Clin. Microbiol. Infect. 2014;20:1-55.

7. Bert F, Larroque B, Dondero F, et al. Risk factors associated with preoperative fecal carriage of extended-spectrum $\beta$-lactamase-producing Enterobacteriaceae in liver transplant recipients. Transpl. Infect. Dis. 2014;16:84-89.

8. Hawkey PM. Multidrug-resistant Gram-negative bacteria: A product of globalization. J. Hosp. Infect. 2015;89:241-247.

9. Fam NS, Defasque S, Bert F, et al. Faecal carriage of extended-spectrum $\beta$-lactamase $(\mathrm{ESBL})$-producing enterobacteria in liver disease patients from two hospitals in Egypt and France: A comparative epidemiological study. Epidemiol. Infect. 2015;143:1247-1255.

10. Arabi YM, Dara SI, Memish Z, et al. Antimicrobial therapeutic determinants of outcomes from septic shock among patients with cirrhosis. Hepatology 2012;56:2305-2315.

11. F. B, B. L, C. P-B, et al. Pretransplant fecal carriage of extended-spectrum $\beta$-lactamaseproducing enterobacteriaceae and infection after liver transplant, France [Internet]. Emerg. Infect. Dis. 2012;18:908-916. [cited 2019 Nov 19] Available from:

http://www.embase.com/search/results?subaction=viewrecord\&from=export\&id=L3648377 79

12. Moreau $\mathrm{R}$, Jalan $\mathrm{R}$, Gines $\mathrm{P}$, et al. Acute-on-chronic liver failure is a distinct syndrome that develops in patients with acute decompensation of cirrhosis. Gastroenterology 2013;144

13. Horan TC, Andrus M, Dudeck MA. CDC/NHSN surveillance definition of health careassociated infection and criteria for specific types of infections in the acute care setting. Am. J. Infect. Control 2008;36:309-332.

14. Angeli P, Bernardi M, Villanueva C, et al. European Association for the Study of the Liver (EASL) Clinical Practice Guidelines for the Management of Patients with Decompensated Cirrhosis [Internet]. J. Hepatol. 2018;69[cited 2019 Oct 29] Available from:

http://linkinghub.elsevier.com/retrieve/pii/S0168827818319664

15. CASFM / EUCAST 2019 - Société Française de Microbiologie [Internet]. [cited 2019 Nov 2] Available from: https://www.sfm-microbiologie.org/2019/01/07/casfm-eucast-2019/

16. Fine JP, Gray RJ. A Proportional Hazards Model for the Subdistribution of a Competing Risk. J. Am. Stat. Assoc. 1999;94:496-509.

17. Gray RJ. A Class of $\$ K \$$-Sample Tests for Comparing the Cumulative Incidence of a 
Competing Risk [Internet]. Ann. Stat. 1988;16:1141-1154.[cited 2020 Jul 3] Available from: https://projecteuclid.org/euclid.aos/1176350951

18. Piano S, Singh V, Caraceni $P$, et al. Epidemiology and Effects of Bacterial Infections in Patients With Cirrhosis Worldwide. [Internet]. Gastroenterology 2019;156:13681380.e10.[cited 2019 Oct 29] Available from: http://www.ncbi.nlm.nih.gov/pubmed/30552895

19. Pereira MR, Scully BF, Pouch SM, et al. Risk factors and outcomes of carbapenemresistant Klebsiella pneumoniae infections in liver transplant recipients. [Internet]. Liver Transpl. 2015;21:1511-9.[cited 2019 Nov 2] Available from: http://www.ncbi.nlm.nih.gov/pubmed/26136397

20. He Q, Liu P, Li X, et al. Risk factors of bloodstream infections in recipients after liver transplantation: a meta-analysis. Infection 2019;47:77-85.

21. Giannella M, Bartoletti M, Campoli C, et al. The impact of carbapenemase-producing Enterobacteriaceae colonization on infection risk after liver transplantation: a prospective observational cohort study. Clin. Microbiol. Infect. 2019;

22. Ponziani FR, Zocco MA, Cerrito L, et al. Bacterial translocation in patients with liver cirrhosis: physiology, clinical consequences, and practical implications. Expert Rev. Gastroenterol. Hepatol. 2018;12:641-656.

23. Dionigi E, Garcovich M, Borzio M, et al. Bacterial Infections Change Natural History of Cirrhosis Irrespective of Liver Disease Severity. Am. J. Gastroenterol. 2017;112:588-596.

24. Kimmann M, Tergast TL, Schultalbers M, et al. Sustained impact of nosocomial-acquired spontaneous bacterial peritonitis in different stages of decompensated liver cirrhosis. PLoS One 2019;14:e0220666.

25. Rieg S, Küpper MF, With K de, et al. Intestinal decolonization of Enterobacteriaceae producing extended-spectrum $\beta$-lactamases (ESBL): A retrospective observational study in patients at risk for infection and a brief review of the literature. BMC Infect. Dis. 2015;15

26. Huttner BD, Lastours $V$ de, Wassenberg $\mathrm{M}$, et al. A 5-day course of oral antibiotics followed by faecal transplantation to eradicate carriage of multidrug-resistant Enterobacteriaceae: a randomized clinical trial. Clin. Microbiol. Infect. 2019;25:830-838. 


\section{FIGURES LEGEND:}

Figure 1. Patients selection

Figure 2. Infection free-survival before and after LT

Figure 3. LRC according to FC

Figure 4. LRC free survival on waitlist

Supplementary Figure S1: Cumulative incidence functions for death and liver transplant. Dotted line represents patients with positive fecal carriage; solid line represents patients with negative fecal carriage.

Supplementary Figure S2: Cumulative incidence functions for death and liver transplant in patients with hepatocellular carcinoma. Dotted line represents patients with positive fecal carriage; solid line represents patients with negative fecal carriage.

Supplementary Figure S3: Cumulative incidence functions for liver transplant in patients with liver-related complications. Dotted line represents patients with positive fecal carriage; solid line represents patients with negative fecal carriage. 
Table 1. Baseline characteristic of 250 cirrhotic patients placed on waitlist and after LT according to ESBLE fecal carriage status.

\begin{tabular}{|c|c|c|c|c|}
\hline & $\begin{array}{l}\text { OVERALL } \\
\text { POPULATION } \\
(\mathbf{N}=\mathbf{2 5 0})\end{array}$ & $\begin{array}{c}\text { FECAL } \\
\text { CARRIERS } \\
(\mathrm{N}=47)\end{array}$ & $\begin{array}{l}\text { NO FECAL } \\
\text { CARRIERS } \\
(\mathrm{N}=203)\end{array}$ & $P$ \\
\hline Sex male (\%) & $76 \%(190)$ & $20 \%(38)$ & $80 \%(152)$ & 0.4 \\
\hline Age mean $\pm S D$ & $57.5 \pm 10$ & $56 \pm 1.5$ & $58 \pm 0.7$ & 0.3 \\
\hline BMI median (range) & $25(22-28)$ & $24(22-28)$ & $26(24-27)$ & 0.7 \\
\hline \multicolumn{5}{|l|}{ Etiology of liver disease (\%) } \\
\hline Viral & $23 \%(59)$ & $20 \%(9)$ & $26 \%(50)$ & $<0.01$ \\
\hline Alcool & $39 \%(99)$ & $30 \%(14)$ & $37 \%(70)$ & $<0.04$ \\
\hline Autoimmune & $6 \%(16)$ & $9 \%(4)$ & $6 \%(12)$ & 0.6 \\
\hline Other & $24 \%(60)$ & $30 \%(14)$ & $24 \%(46)$ & 1 \\
\hline MELD-score median (range) & $19(12-28)$ & $23(19-28)$ & $18(16-20)$ & $<0.01$ \\
\hline HCC (\%) & $21 \%(53)$ & $11 \%(6)$ & $23 \%(47)$ & $<0.01$ \\
\hline Norfloxacine (\%) & $16 \%(39)$ & $15 \%(6)$ & $85 \%(33)$ & 0,9 \\
\hline Rifaximine (\%) & $16 \%(39)$ & $20 \%(8)$ & $79 \%(31)$ & 0,7 \\
\hline $\begin{array}{l}\text { Time on waitlist } \\
\text { median (range) }\end{array}$ & $4(3-4)$ & $3(1-4)$ & $4(3-5)$ & 0.2 \\
\hline $\begin{array}{l}\text { Time of Infection } \\
\text { on waitlist } \\
\text { median (range) }\end{array}$ & $3(2-4)$ & $2(1-3)$ & $4(2-5)$ & 0.06 \\
\hline $\begin{array}{l}\text { Time of Liver related } \\
\text { complications on waitlist } \\
\text { median (range) }\end{array}$ & $3(2-4)$ & $2(1-3)$ & $3(3-4)$ & 0.2 \\
\hline LRC at baseline & $49 \%(124)$ & $59 \%(28)$ & $47 \%(96)$ & \\
\hline $\begin{array}{l}\text { Antibiotic treatment in the } \\
\text { last } 3 \text { months before LT (\%) }\end{array}$ & $10 \%(26)$ & 7 (27\%) & $19(73 \%)$ & 0.3 \\
\hline $\begin{array}{l}\text { Hospitalization in ICU or } \\
\text { SICU in the past } 3 \text { months } \\
\text { before LT (\%) }\end{array}$ & $12 \%(30)$ & 7 (23\%) & $23(78 \%)$ & 0.6 \\
\hline $\begin{array}{l}\text { Time of Infection } \\
\text { after LT } \\
\text { median (range) }\end{array}$ & $15(12-21)$ & $21(8-28)$ & $13.5(11-19)$ & 0.2 \\
\hline
\end{tabular}


BMI: body mass index; MELD: model of end stage liver disease; HCC: hepatocellular carcinoma; ESBLE: extended spectrum beta-lactamase-producing Enterobacteriacae.

This article is protected by copyright. All rights reserved 


\begin{tabular}{|c|c|c|c|c|}
\hline & $\begin{array}{c}\text { FECAL } \\
\text { CARRIAGE } \\
\text { POSITIVE } \\
(n=47)\end{array}$ & $\begin{array}{c}\text { FECAL } \\
\text { CARRIAGE } \\
\text { NEGATIVE } \\
(n=203)\end{array}$ & $H R(C l 95 \%)$ & $P$ value \\
\hline \multicolumn{5}{|l|}{ BEFORE LT } \\
\hline $\begin{array}{l}\text { Follow-up median } \\
\text { (range) (months) }\end{array}$ & $3(4-1)$ & $4(3-5)$ & & \\
\hline $\begin{array}{l}\text { Cumulative Incidence of infectic } \\
\text { (Cl 95\%) }\end{array}$ & & & & \\
\hline 6 months & $18 \%(8-37)$ & $15 \%(10-22)$ & & \\
\hline $\mathrm{n}$ at risk & 11 & 74 & & \\
\hline 12 months & $21 \%(10-40)$ & $18 \%(13-26)$ & & \\
\hline $\mathrm{n}$ at risk & 6 & 36 & & \\
\hline $\begin{array}{l}\text { Infections Free Survival rate \% } \\
\text { (Cl 95\%) }\end{array}$ & & & $1.5(0.6-3.7)$ & 0.28 \\
\hline 6 months & $80 \%(36)$ & $82 \%(129)$ & & \\
\hline $\mathrm{n}$ at risk & 11 & 74 & & \\
\hline 12 months & $70 \%(42)$ & $75 \%(167)$ & & \\
\hline $\mathrm{n}$ at risk & 5 & 36 & & \\
\hline
\end{tabular}

Cumulative Incidence of events \%

$$
\text { (CI 95\%) }
$$

$\begin{array}{lcc}\mathbf{6} \text { months } & 41 \%(28-59) & 27 \%(20-35) \\ \mathbf{n} \text { at risk } & 9 & 59 \\ \mathbf{1 2} \text { months } & 48 \%(35-67) & 34 \%(27-42) \\ \mathbf{n} \text { at risk } & 4 & 26\end{array}$

LRC free survival rate $\%$ (Cl 95\%)

\begin{tabular}{lcc}
$\mathbf{6}$ months & $50 \%(38)$ & $68 \%(144)$ \\
$\mathbf{n}$ at risk & 9 & 59 \\
$\mathbf{1 2}$ months & 0 & $53 \%(177)$ \\
$\mathbf{n}$ at risk & 3 & 26 \\
\hline
\end{tabular}

Waitlist mortality \%

(Cl 95\%) *

0. 721

6 months

$12.7 \%(5.1-\quad 10.4 \%(6.7-$
$24.1 \%)$
$15.1 \%)$ 


\section{2 months}

$14.9 \%(6.3-\quad 11.9 \%(7.9-$

$26.7 \%) \quad 16.9 \%)$

Waitlist mortality in patients

Underwent LT for HCC \% *

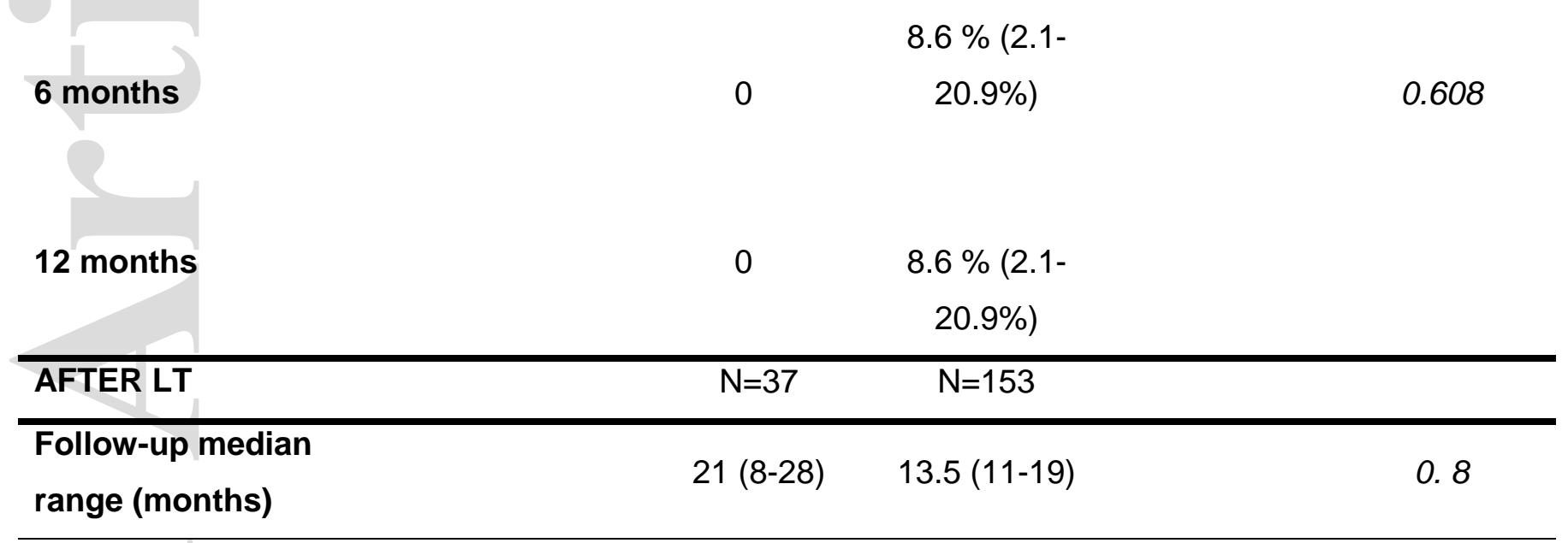

Cumulative Incidence of infections \%

(Cl 95\%)

\begin{abstract}
6 months
\end{abstract}
n at risk

12 months

$\mathrm{n}$ at risk

Infections Free Survival rate \%

(Cl 95\%)

12 months

$\mathrm{n}$ at risk $\begin{array}{cc}17 \%(7-38) & 15 \%(10-22) \\ 23 & 74\end{array}$

$\begin{array}{cc}27 \%(15-49) & 18 \%(13-26) \\ 20 & 36\end{array}$

$\begin{array}{cc}35 \%(34) & 44 \%(136) \\ 3 & 17\end{array}$




\begin{tabular}{|c|c|c|c|c|}
\hline Sex male & 0.3 & $1.33(0.75-2.38)$ & NS & \\
\hline Age mean $\pm S D$ & 0.01 & $1(1-1.002)$ & NS & \\
\hline MELD-score > 19 (median) & 0.01 & $3.1(1.98-5)$ & 0.01 & $3.0(1.79-5.17)$ \\
\hline HCC & $\mathbf{0 . 0 3}$ & $0.5(0.2-0.9)$ & NS & \\
\hline Faecal carriers & 0.04 & 1.7(1.01.-2.8) & NS & \\
\hline Etiology & 0.15 & $1.12(0.96-1.32)$ & NS & \\
\hline Invasive procedures & 0.65 & $1.2(0.5-2.7)$ & NS & \\
\hline Infections before LT wo SBP & 0.05 & $0.6(0.3-1)$ & NS & \\
\hline \multicolumn{5}{|l|}{ Time on waitlist $>4$ months } \\
\hline (median) & $<0.001$ & $3.4(1.92-6.21)$ & NS & \\
\hline \multicolumn{5}{|l|}{ Time of Infection } \\
\hline on waitlist $<3$ months (median) & $<0.001$ & $0.9(0.8-0.9)$ & $<0.001$ & $4.13(2.13-7.9)$ \\
\hline \multicolumn{5}{|l|}{ Antibiotic treatment in the last 3} \\
\hline months before LT & 0.01 & $2.2(1.2-3.9)$ & NS & \\
\hline $\begin{array}{l}\text { Hospitalization in ICU or SICU } \\
\text { in the past } 3 \text { months before LT }\end{array}$ & 0.01 & $2.196(1.26-3.8)$ & 0.07 & $1.7(0.9-3.15)$ \\
\hline
\end{tabular}

LRC: Liver related complications; ICU: intensive care unit; SICU: semi- intensive care unit; wo: without; HCC: hepatocellular carcinoma.

*The multivariate analysis was adjusted for LRC at baseline. To take into account the competing risk of LT on LRC rate, the model was adjusted for the number of events that occurs during the waitlist time lapse. 
Figure 1. Patients Selection

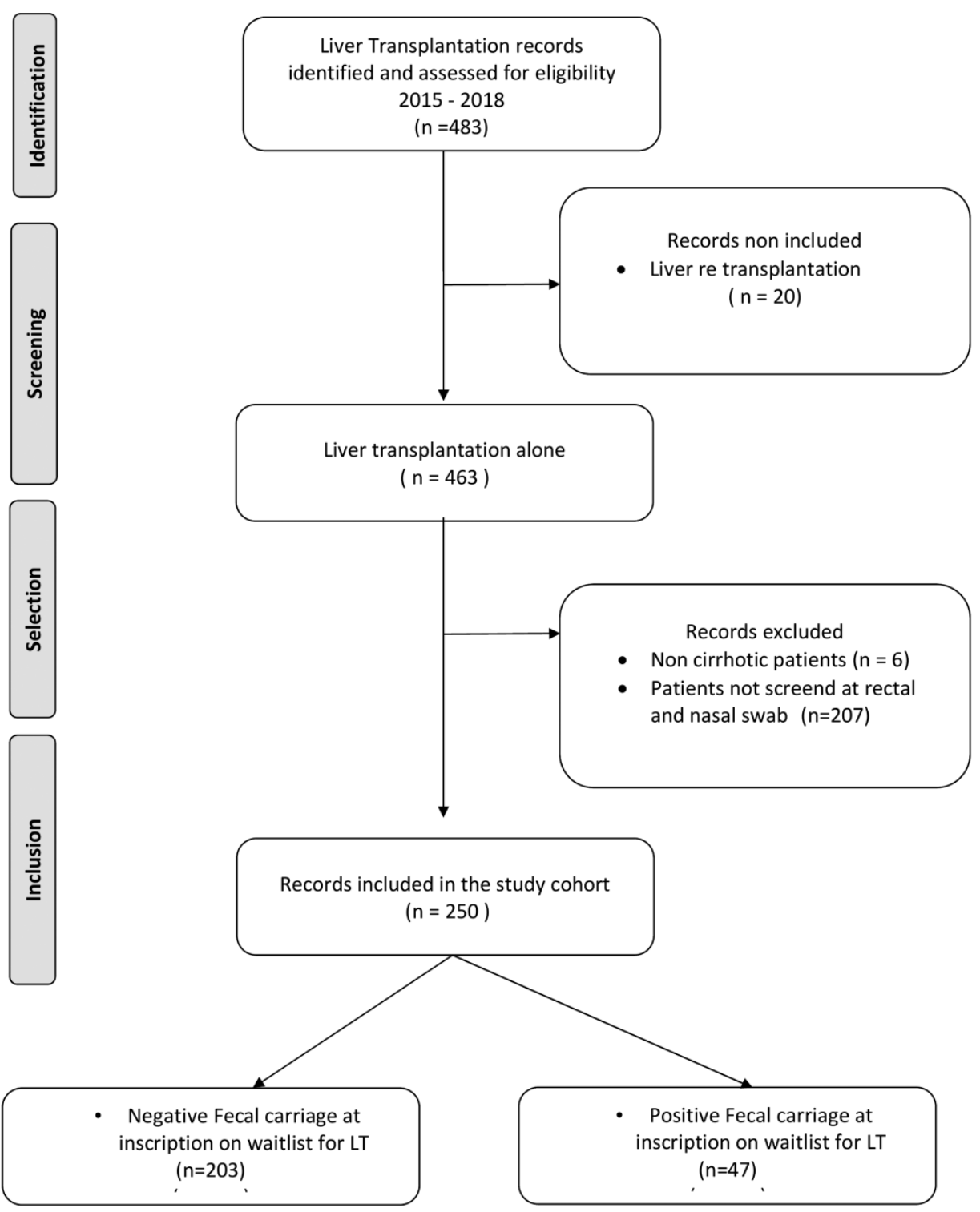

lt_25897_f1.tif

This article is protected by copyright. All rights reserved 


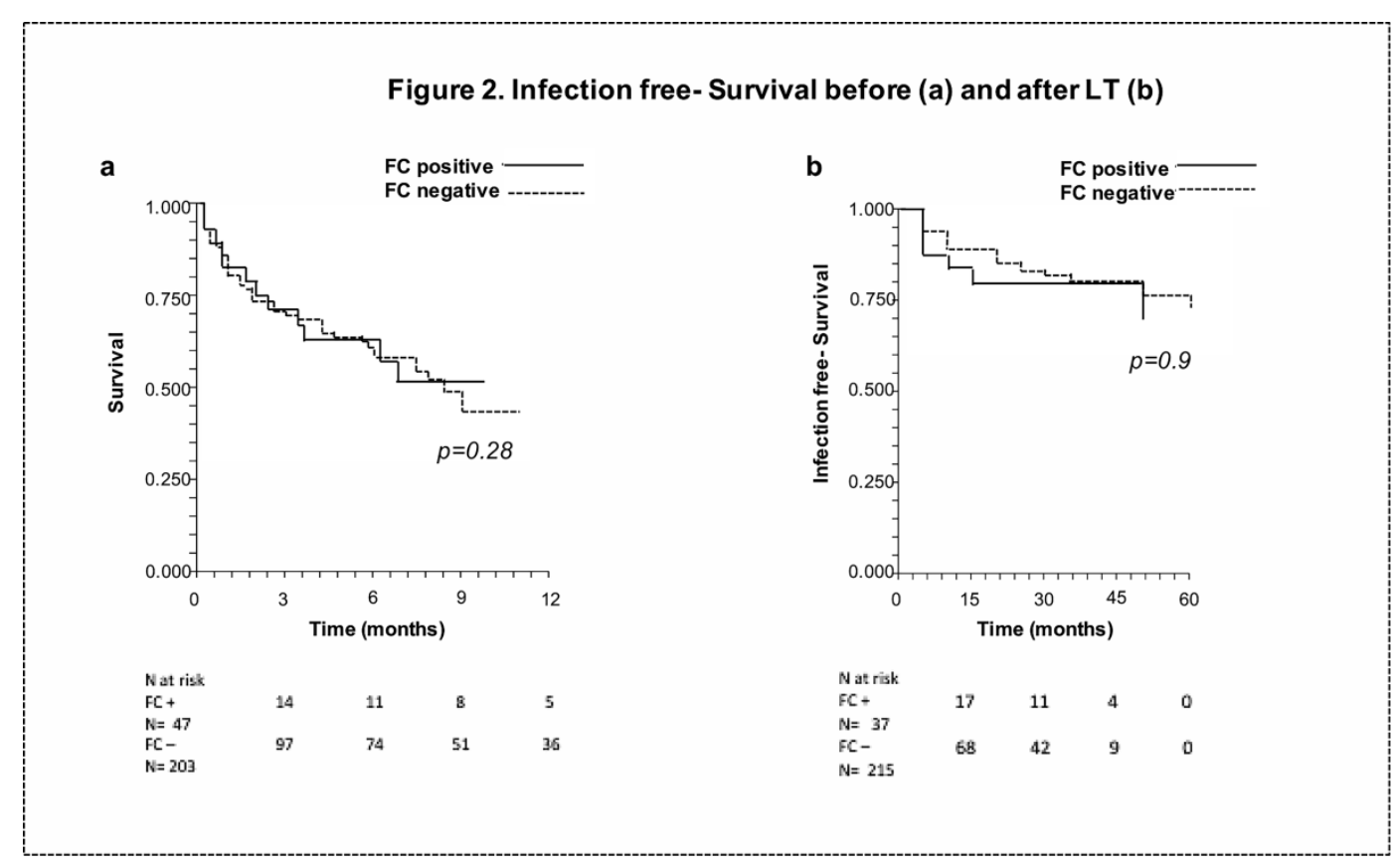

lt_25897_f2.tif

This article is protected by copyright. All rights reserved 
Figure 3. LRC according to EBLSE faecal carriers
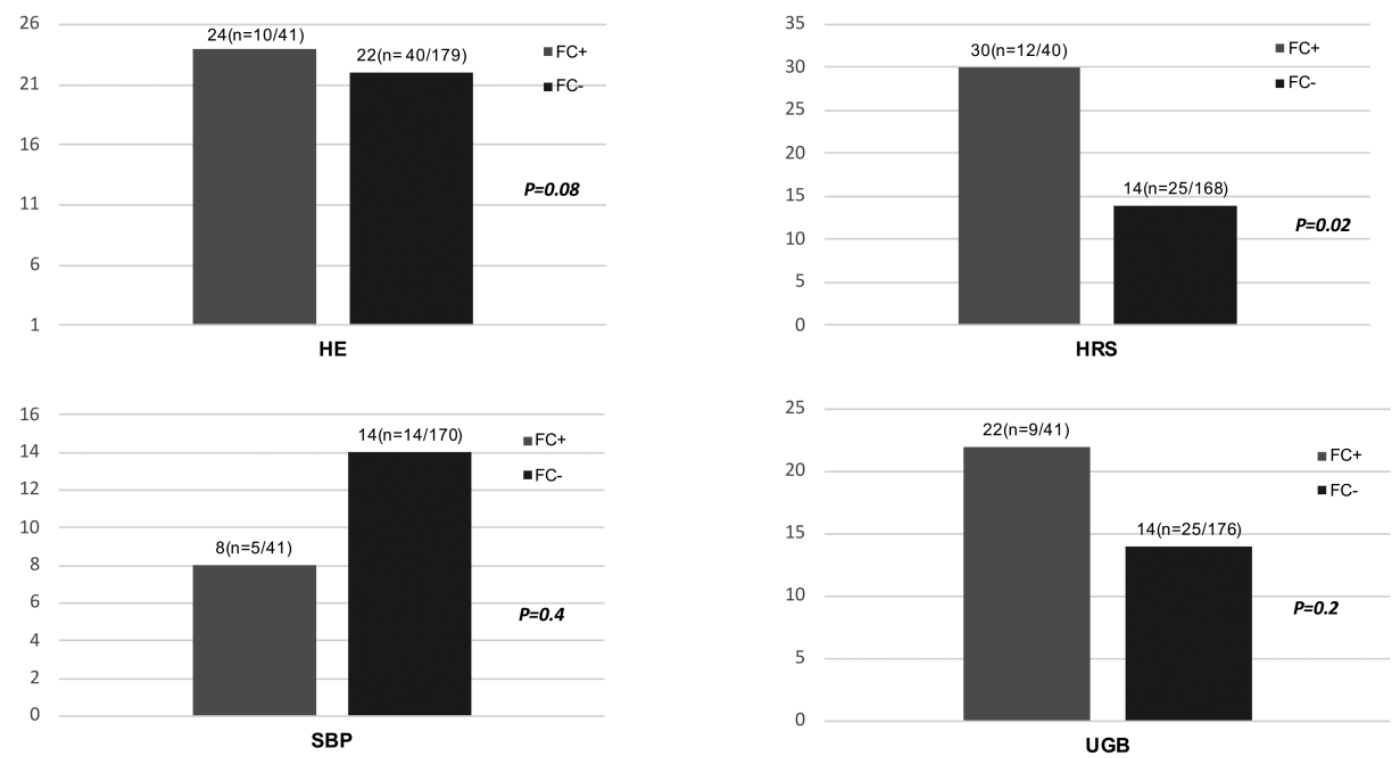

HE: Hepatic encephalopaty; HRS: Hepato-renal syndrome; SBP: spontaneous bacterial peritonitis; UGB: Upper gastrointestinal bleeding

lt_25897_f3.tif 
Figura 4. Liver-related-complications-free-survival on waitlist according to fecal carriage

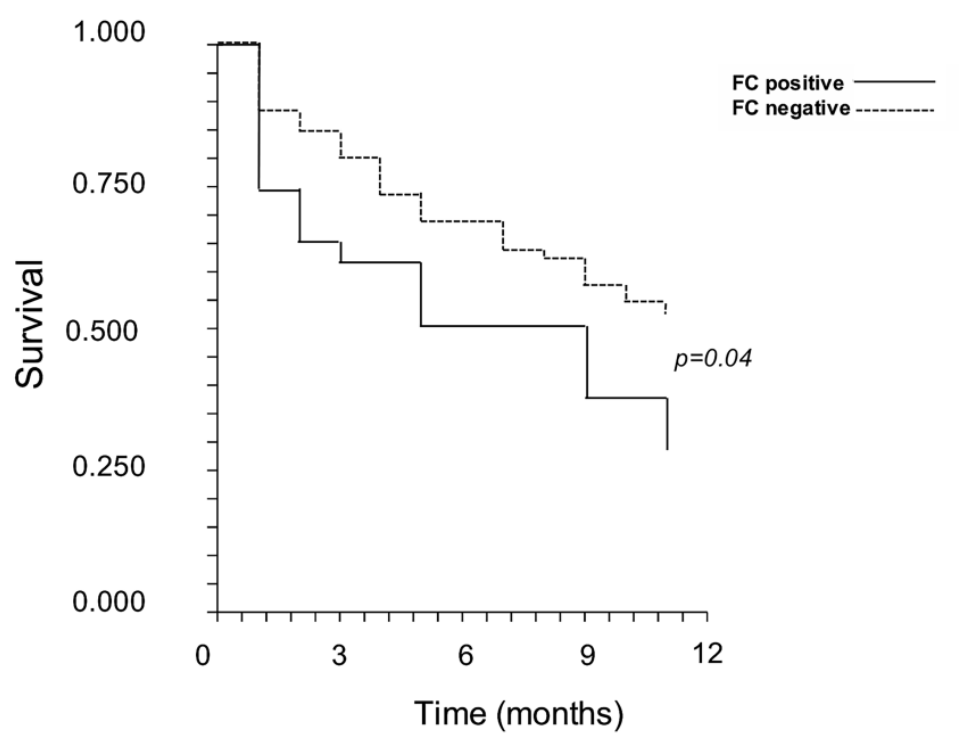

$\begin{array}{llllr}\mathrm{N} \text { at risk } & & & & \\ \mathrm{FC}+ & 15 & 9 & 8 & 3 \\ \mathrm{~N}=47 & & & & \\ \mathrm{FC}- & 90 & 59 & 45 & 26 \\ \mathrm{~N}=203 & & & \end{array}$

lt_25897_f4.tif

This article is protected by copyright. All rights reserved 